\title{
Does Temperature Effects the Growth of Cracks in a Submarine Volcano That is under a Hot-spot?
}

\author{
M. Tsili, D. Zacharopoulos* \\ Department of Civil Engineering, Democritus University of Thrace, Xanthi, Greece \\ *Corresponding author: martsili@otenet.gr
}

\begin{abstract}
In this paper we investigated if temperature effects the growth of cracks in a submarine volcano that was under a hot-spot. We based upon theory of fracture mechanics for and we showed that the undersea volcano will be exploded and a sea-whirpool will be gene- rated. Our findings are verified by studies that recorded the above phenolmenon in certain places of the Earth. Thus we concluded that temperature significantly contributes to the growth of cracks.
\end{abstract}

Keywords: effect of temperature, growth of cracks, theory of fracture mechanics, submarine volcano, hot- spot

Cite This Article: M. Tsili, and D. Zacharopoulos, "Does Temperature Effects the Growth of Cracks in a Submarine Volcano That is under a Hot-spot?” American Journal of Mechanical Engineering, vol. 5, no. 2 (2017): 58-63. doi: 10.12691/ajme-5-2-4.

\section{Introduction}

The purpose of this paper is to investigate if temperature effects the growth of cracks in an submarine volcano that is under a hot-spot. For that reason we will base upon fracture mechanics theory and we will distinguish two cases: i) the volcano had a macrocrack and ii) the volcano had not a macrocrack.

\section{The Problem and Its Physical Approximation}

\section{i) The structure of the Earth}

The inner of the Earth consists of three elastic layers indicated in Figure 1: the crust, the mantle and the core [1-10]. The crust divides into continental and oceanic. The last is less thicker than condinental crust and consists mainly from basalt rock [10-15]. Volcanism is an open path, originated in the inner core of the Earth and alloys the flow of lava by erupting liquid rocks and gasses from mantle to the surface of the crust $[16,17,18,19,20]$. Submarine volcano is a volcano that lies either: in the bottom of the ocean, or in the ocean crust.

Hot spots [21] develop above the mantle plumes and are places within the mantle, where rock melt to generate magma. The produced magma rises thought the rigid plates of lithosphere and create active submarine volcanoes as indicated in Figure 2. The above is inferred as anomalous volcanism $[10,22,23,24,25,26,27]$.

ii) The 2D- model

We deal in 2D-plane with a submarine volcano ABCD, that lies in the ocean crust and is under a hot-spot, as indicated in Figure 3. The volcano consists from homogenous material: basalt rock. We will study the mechanic behavior of its orthogonal KLNM. In present work tensile and compressive stresses are positive and negative respectively.

Initially, At $\mathrm{t}=0$ the volcano $\mathrm{ABCD}$ and therefore its orthogonal KLNM was in non-active state and had a temperature $\theta_{0}$ of the order of $0^{\circ} \mathrm{C}$. This temperature is indicative in the bottom of the ocean $[10,14]$.

At $\mathrm{t}>0$ a hot-spot whose temperature is about 200$300^{\circ} \mathrm{C}$ comes to contact with the lower side of the orthogonal KLNM indicated in Figure 2 and Figure 3. As a result of the above the orthogonal KLNM of the volcano is heating. Since basalt is an elastic material it follows:

$$
\begin{aligned}
\varepsilon_{\mathrm{zz}}(\mathrm{t}) & =\sigma_{\mathrm{zz}}(\mathrm{t}) / \mathrm{E}+\alpha \Delta \theta(\mathrm{t}) \\
& =\sigma_{\mathrm{zz}}(\mathrm{t}) / \mathrm{E}+\alpha\left[\theta(\mathrm{t})-\theta_{o}\right]
\end{aligned}
$$

where $\varepsilon_{z z}, \sigma_{z z}, E, \alpha, \Delta \theta$ : are respectively the normal strain the axial stress, the elasticity modulus, the coefficient of thermical dilation and the difference of temperature from its initial value $\theta_{0}$. Since both sides $\mathrm{KL}$ and $\mathrm{MN}$ of orthogonal KLNM are fixed it follows:

$$
\mathrm{u}_{\mathrm{z}}=0
$$

where $\mathrm{u}_{\mathrm{z}}$ is the axial displacement. The last results

$$
\varepsilon_{\mathrm{zz}}=0 .
$$

Substituting the above into (2.1), it is possible to obtain:

$$
\sigma_{\mathrm{zz}}(\mathrm{t})=-\mathrm{E} \alpha \Delta \theta(\mathrm{t})=-\mathrm{E} \alpha\left[\theta(\mathrm{t})-\theta_{O}\right]<0 \text { for } \mathrm{t}>0
$$

that is an axial compressive stress $\sigma_{z z}(t)$ is produced in the orthogonal KLNM during heating. 


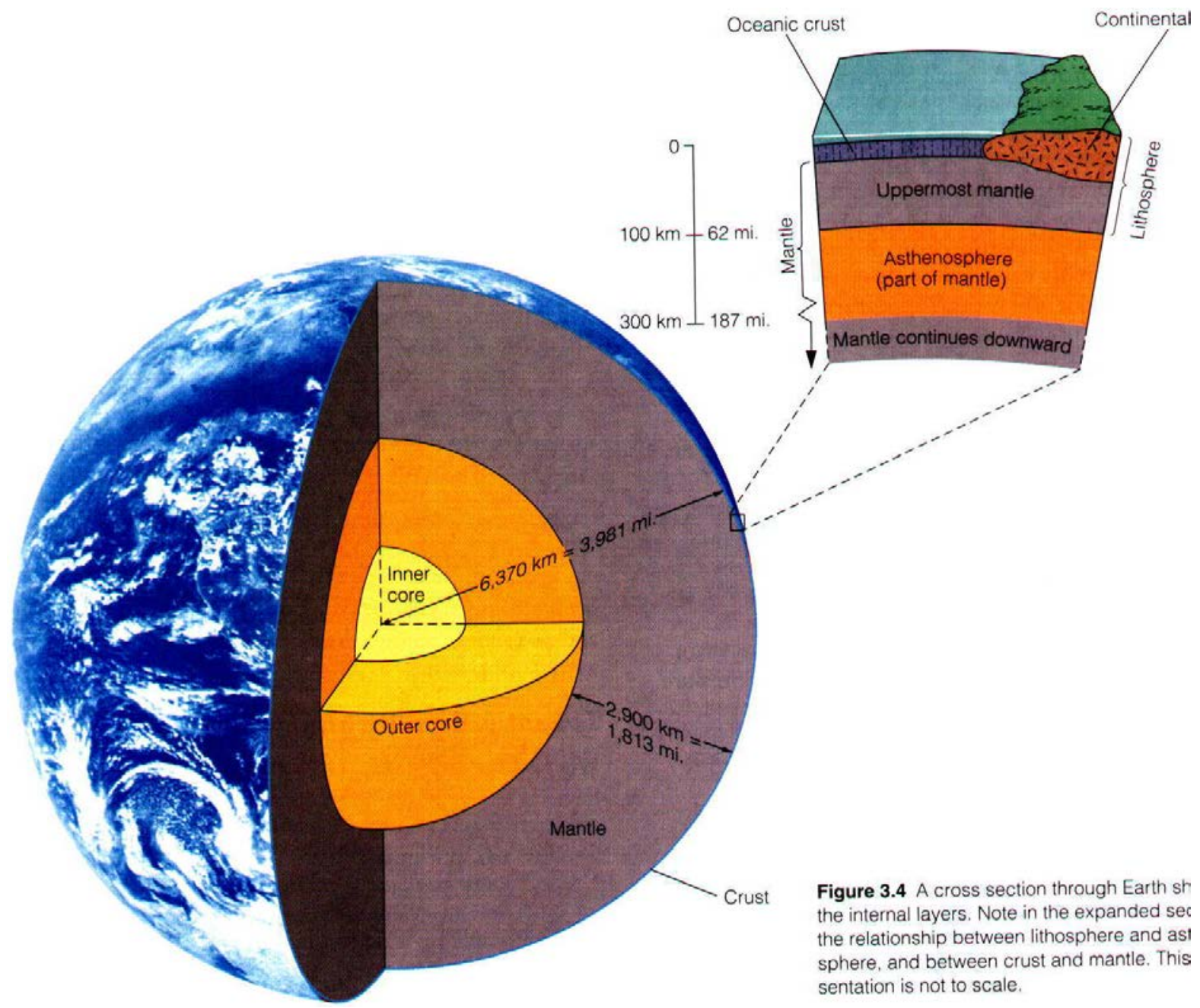

Figure 1. The structure of the Earth. Taken from: [[1], p.3]

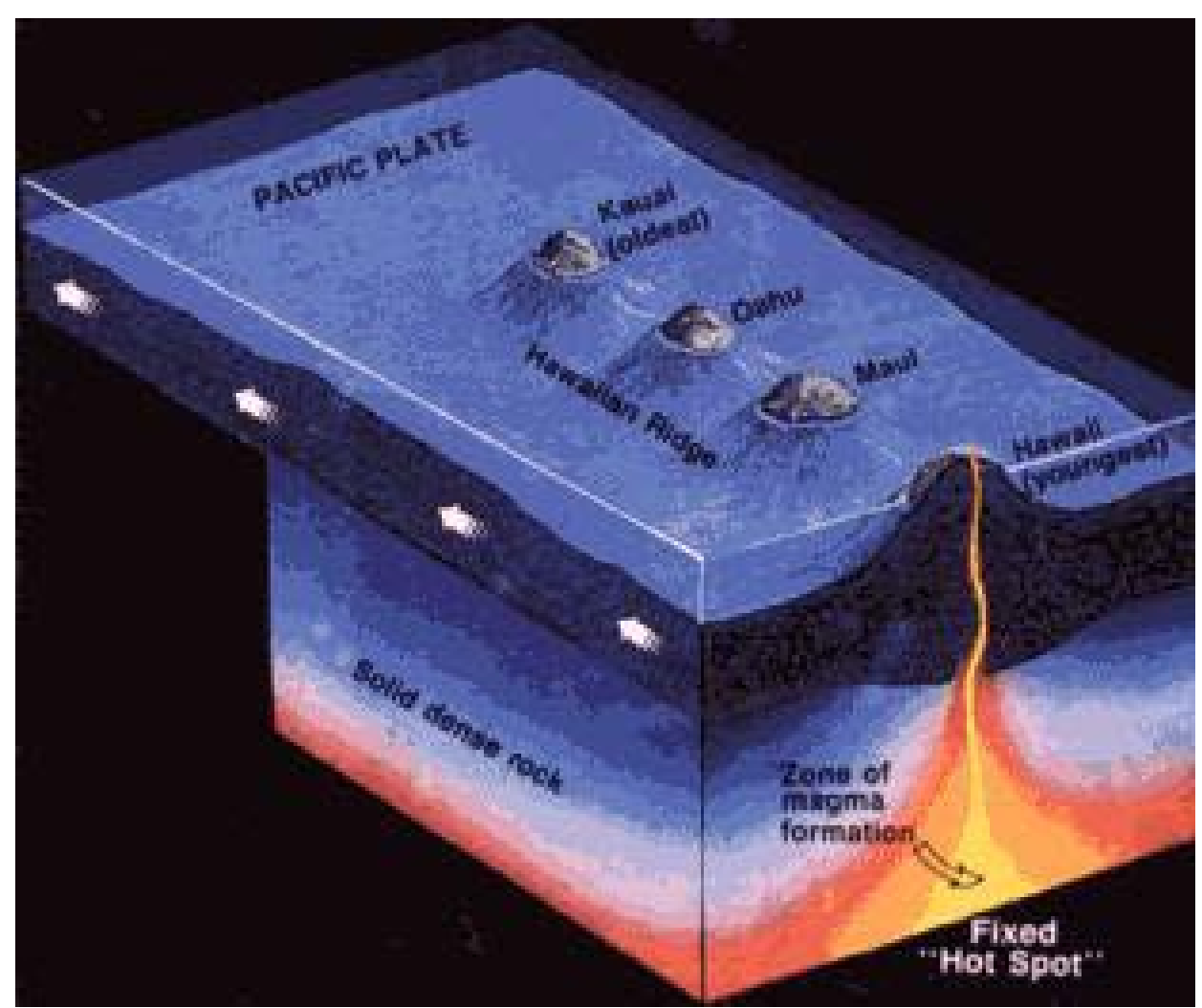

Figure 2. A 3D view of a hot spot in Havai submarine volcano. Taken from [27] 


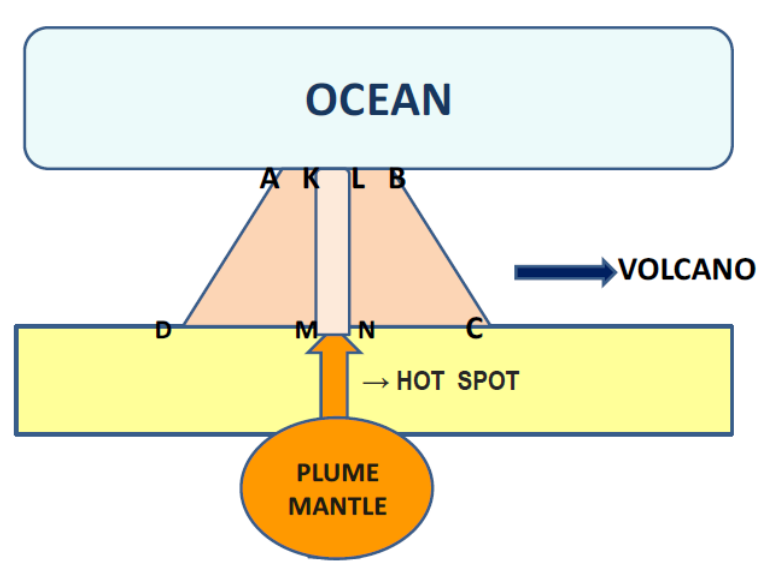

Figure 3. A $2 D$ view of a submarine hot - spot volcano ABCD

\section{The Growth of Crack}

The cracks are divided to the following categories: structural, macrocracks, mesocraks and microcracks [[28], p.16]. Structural are the cracks whose length varies from some hundrend metres until some kilometres. Macroscopic are ordinary cracks whose length varies from some centimeters until some metres. Mesocracks are the cracks whose length varies from some $\mu$ icrometres until some millimeters. Some of them are vissible by naked eye and some others are invissible. Finally microcracks are invissible cracks whose length are of the order of $\mu$ icrometres.

We distinguish the following cases:

\section{i) The orthogonal KLNM of the volcano had no vissible cracks}

However all bodies have invissible cracks [29,30]. This means that our volcano initially had mesomicrocracks. Basalt is a very strong rock and belongs to same category with chalazites, with the sense that both rocks have similar mechanical properties under compression [31,32]. With other words the process of the fracture of basalt is similar with those of chalazites.

As we stated earlier at $t=0$ the temperature of orthogonal KLNM was $\theta_{0}$. At $\mathrm{t}=\mathrm{t}_{1}>0$ the temperature of the orthogonal KLNM increases due to contact with the hot -spot and becomes $\theta\left(\mathrm{t}_{1}\right)$ such that:

$$
\theta\left(\mathrm{t}_{1}\right) \approx 0.6\left|\sigma_{\mathrm{f}}\right| / \mathrm{E} \alpha+\theta_{O}>\theta_{O}
$$

where $\left|\sigma_{\mathrm{f}}\right|$ is the absolute magnitude of the stress fracture of basalt under compression. Then from (2.4) it results that $\sigma_{\mathrm{zz}}=0.6\left|\sigma_{\mathrm{f}}\right|$. At this phase: i) new invissible mesomicrocracks are producing and ii) the preexisting invissible microcracks start growing [[31], pp., 118-119].

At $\mathrm{t}=\mathrm{t}_{2}>\mathrm{t}_{1}$ the temperature ascends to $\theta\left(\mathrm{t}_{2}\right)$ and lies:

$$
2\left|\sigma_{\mathrm{f}}\right| / 3 \mathrm{E} \alpha+\theta_{o} \leq \theta\left(\mathrm{t}_{2}\right) \leq 0.75\left|\sigma_{\mathrm{f}}\right| / \mathrm{E} \alpha+\theta_{o}
$$

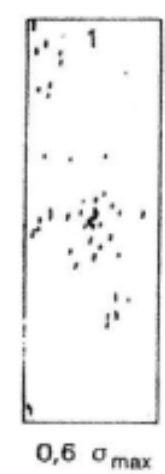

(a)

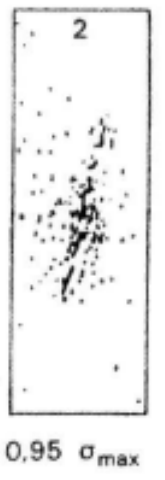

(b)

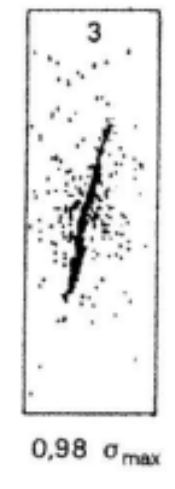

(c)

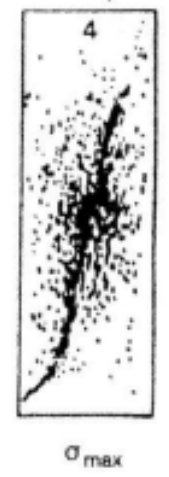

(d)

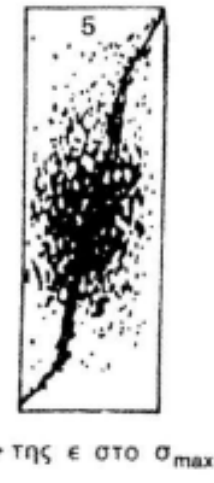

(e)

Figure 4. The process of the fracture of an orthogonal specimen of a very strong rock that is under a compressive load $\sigma$ described at five phases (a): The load becomes $\sigma=0.6 \sigma_{\max }$, where $\sigma_{\max }$ is the stress fracture and new microcracks are produced. (b): The load becomes $\sigma=0.95 \sigma_{\max }$ and the microcracks start unite and forms small vissible cracks $(\mathrm{c})$ : As the load becomes $\sigma=0.98 \sigma_{\max }$, the small vissible cracks unite and form a big crack which fastly increases and (d): is ready to split the specimen into two pieces as $\sigma=\sigma_{\max }(\mathrm{e})$ :The final result is the fracture of the specimen. At the above process a stiff machine has been used. Taken from [[31], p.118]

Then from (2.4) it follows that $2 / 3\left|\sigma_{\mathrm{f}}\right| \leq \sigma_{\mathrm{zz}} \leq 0.75\left|\sigma_{\mathrm{f}}\right|$. At present phase an increasing rate of arised mesomicrocracs is recorcorded [[31], pp.118-119].

Finally at $\mathrm{t}=\mathrm{t}_{3}>\mathrm{t}_{2}$ the temperature ascends to $\theta\left(\mathrm{t}_{3}\right)$ such that:

$$
\theta\left(\mathrm{t}_{3}\right) \approx\left|\sigma_{\mathrm{f}}\right| / \mathrm{E} \alpha+\theta_{o} .
$$

Then from (2.4) it follows that $\sigma \mathrm{zz} \approx\left|\sigma_{\mathrm{f}}\right|$ and a vissible crack is producing due to the union of mesomicrocracks. The last is fastly growing and splits the orthogonal KLNM into two pieces [[31], pp.118-119]. The process we described above and the final result indicated in Figure 4 and Figure 5 respectively.

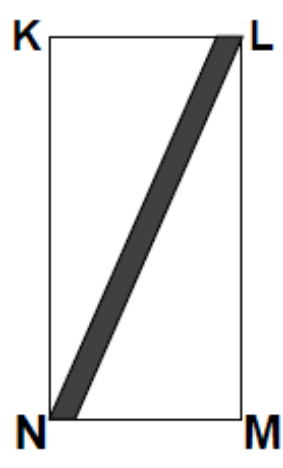

Figure 5. At time $t=t_{3}$ the orthogonal KLMN of the volcano splits into two pieces 


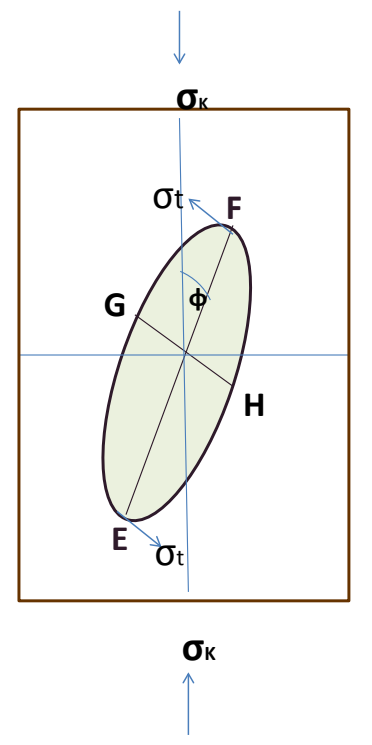

Figure 6. An elliptic crack with a big axis EF forms an angle $0 \leq \varphi<90^{\circ}$ with the vertical direction and a small axis $\mathrm{GH}$

\section{ii) The orthogonal KLMN had a vissible crack}

Assume that the orthogonal KLMN of the volcano ABCD had a vissible elliptic crack with a big axis $E F=2 c$ and small axis $\mathrm{GH}=2 \mathrm{~b}$. An angle $0 \leq \varphi<90^{\circ}$ was formed between the vertical direction and the small axis indicated in Figure 6. The length $\mathrm{EF}=2 \mathrm{c}$ ranged between some meters until some hundred meters. Therefore our crack is characterized as macrostructural [[28], p.16] and the laws of classical fracture mechanics continue to hold.

Since at $\mathrm{t}=0$ the orthogonal KLNM was free of external stress, it results that the ends of the ellipse $\mathrm{E}$ and $\mathrm{F}$ were also free of stress. At $\mathrm{t}>0$ the temperature of the orthogonal KLNM increases $\theta(\mathrm{t})$. Then a compressive stress $\sigma_{\mathrm{zz}}$ is generated given by (2.4). As a consequence of the above, tensile stresses $\sigma_{\mathrm{t}}$ are development at the ends of the crack $\mathrm{E}$ and $\mathrm{F}$ [29,30,31,33]. The last is given by:

$$
\sigma_{\mathrm{t}}(\mathrm{t})=\sigma_{\mathrm{zz}}(\mathrm{t}) \cos \varphi(\cos \varphi-1) / \xi_{O}>0
$$

where $\xi_{\mathrm{o}}$ is a parameter of the ellipse [31,33].

At a particular time moment $\mathrm{t}=\mathrm{t}_{\mathrm{k}}$ the temperature of the orthogonal KLNM becomes:

$$
\theta\left(\mathrm{t}_{\mathrm{k}}\right)=\theta_{\mathrm{o}}+(2 \gamma \mathrm{E} / \pi \mathrm{c})^{1 / 2} \xi_{o} / \cos \varphi(1-\cos \varphi) \alpha \mathrm{E}
$$

where $\gamma$ is the surface energy of the basalt. Then (2.4) due to the above is written as:

$$
\sigma_{\mathrm{zZ}}\left(\mathrm{t}_{\mathrm{K}}\right)=(2 \gamma \mathrm{E} / \pi \mathrm{c})^{1 / 2} \xi_{o} / \cos \varphi(1-\cos \varphi) .
$$

Consequently (3.4) because of (3.6) results to:

$$
\sigma_{\mathrm{t}}\left(\mathrm{t}_{\mathrm{K}}\right)=\left(2 \gamma^{\cdot} \mathrm{E} / \pi \mathrm{c}\right)^{1 / 2} \text {. }
$$

The above physically means that at particular time moment $\mathrm{t}=\mathrm{t}_{\mathrm{k}}$, the tensile stress coincides with the critical stress $[30,31,37]$. As a consequence of the above the crack will grow and the direction of propagation can be calculated by [31,33]:

$$
\mathrm{d} \sigma_{\mathrm{t}}\left(\mathrm{t}_{\mathrm{K}}\right) / \mathrm{d} \varphi=0
$$

where $\sigma_{t}\left(t_{K}\right)$ is given by (3.4). From the above we result:

$$
\varphi_{1}=0^{\circ} \text { and } \varphi_{2}=60^{\circ}
$$

Also the tensile stress $\sigma_{t}\left(t_{K}\right)$ must satisfy $[31,33]$ :

$$
\mathrm{d}^{2} \sigma_{\mathrm{t}}\left(\mathrm{t}_{\mathrm{K}}\right) / \mathrm{d} \varphi^{2}<0
$$

The last is satisfied for $\varphi=\varphi_{1}=0$.

The solution $\varphi 1=0$ means that crack will grow at the ends of ellipse and will propagate parallelly to the axial compressive load $\sigma_{\mathrm{K}}$. The last has been experimentally verified [31,33-38,40]. From the other hand the preexisting elliptic crack will vanish and the propagation of crack will due to the union of invissible mesomicrocracks [33,39]. At continuity the crack will grow and will split orthogonal KLMN in Figure 7, Figure 8 and Figure 9 for cases of: central, lowest and upper crack respectively. (a)

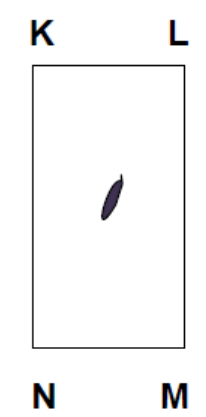

(b)

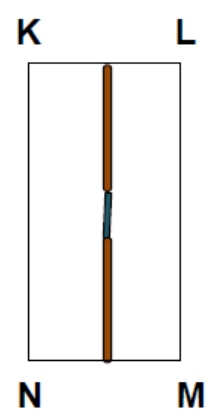

Figure 7. (a) The orthogonal KLMN has a central elliptic crack. (b): The crack fastly grows at the ends of big axis of ellipse and paralelly directs to compressive load $\sigma_{\mathrm{zz}}[29-38,40]$. The elliptic crack vanishes and the propagation of crack in that area due to the union of invissible mesomicrocracks [39]

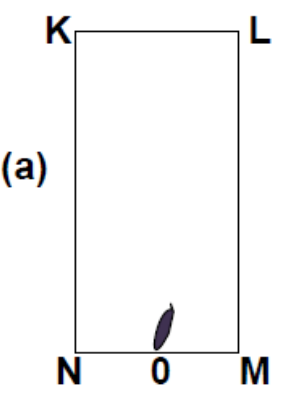

(b)

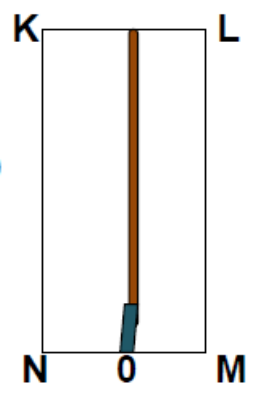

Figure 8. (a) The orthogonal KLMN had an elliptic crack such that the lowest end of the bix axis 0 belonged to NM side. (b) The crack fastly grows at the upper end of the big axis of the ellipse and paralelly directs to the compressive load $\sigma_{\mathrm{zz}}[31,33,34,35,36]$. The elliptic crack vanishes and the propagation of the crack in that area due to the union of invissible microcracks [39] (a)

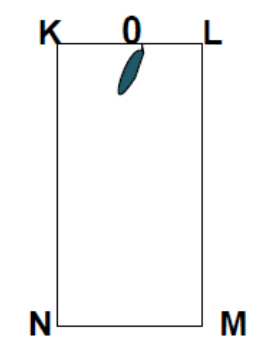

(b)

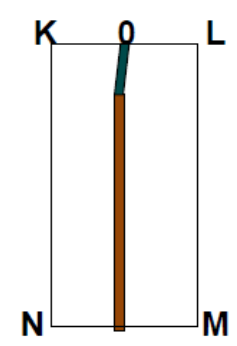

Figure 9. (a) The orthogonal KLMN had an elliptic crack such that the up- per end of the bix axis 0 belonged to KL side (b) The crack fastly grows at the lower end of the big axis of the ellipse and paralelly directs to the compressive load $\sigma_{\mathrm{zz}}[31,34,35,36,37,38,40]$. The elliptic crack vanishes and the propagation of crack in that area due to the union of invissible microcracks [39] 
(a)

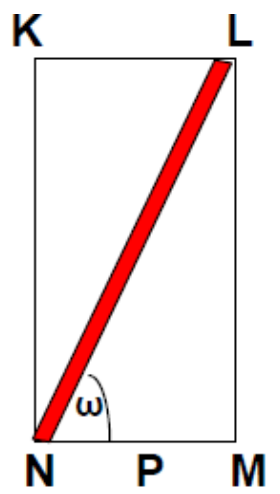

(b)

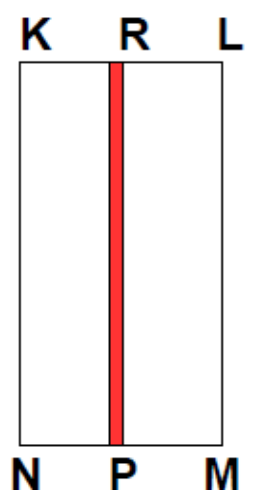

Figure 10. A view of the pipe duke (with red lines), due to the splitting of the orthogonal KLNM into two pieces for the cases that the last: (a) had no pre-existed visible cracks and (b) had a vissible elliptic crack

\section{The Erruption of the Volcano and the Formation of a Sea-whirpool}

\section{i) The erruption of the submarine volcano}

As a result of the process we described above the orthogonal KLNM will split into two pieces and a pipe duke will be formed. The last is illustrated in Figure 10. for both cases we studied. After the fracture the pipe duke will immedially be filled up with the magma of hot-spot. Then the mass $\mathrm{mm}$ of magma will be under a force $\mathrm{F}$ :

$$
\mathrm{F}=\mathrm{m}_{\mathrm{m}}(\Delta \mathrm{v} / \Delta \mathrm{t})
$$

where:

$$
\Delta \mathrm{t}=\mathrm{t}-\mathrm{t}_{\mathrm{o}} \text { and } \Delta \mathrm{v}=\mathrm{v}-\mathrm{v}_{\mathrm{o}}
$$

where: $t_{0}$ and $v_{0}$ are respectively the time moment at which the magma filled up the pipe duke of volcano and its velocity.

Since $\Delta \mathrm{t} \rightarrow 0$, from (4.1) it results that $\mathrm{F} \rightarrow+\infty$ which means that volcano will be errupted. After that pipe duke will be filled up with the water of the ocean as indicated in Figure 11.

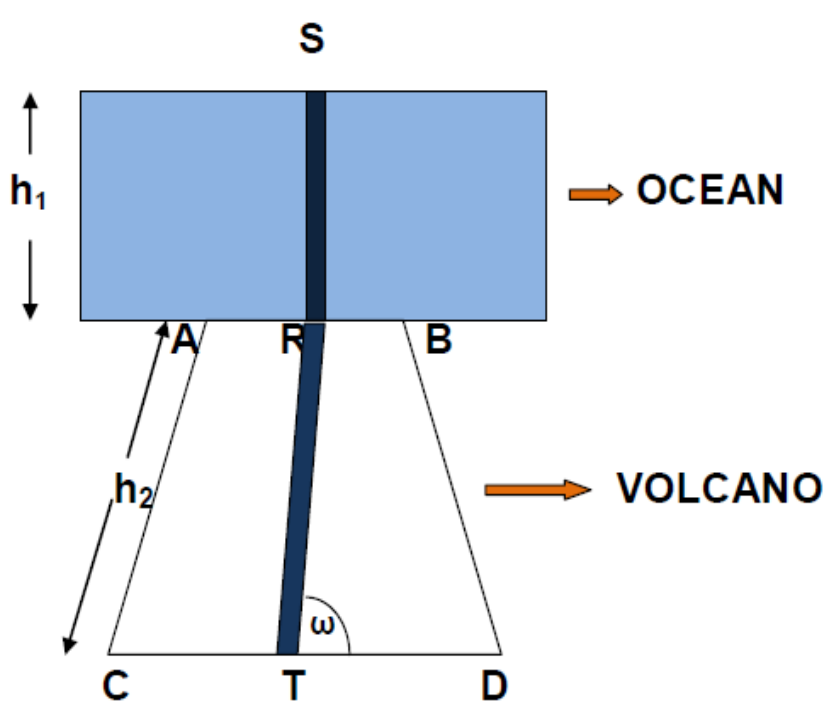

Figure 11. An approximated $2 \mathrm{D}$ view of the erupted submarine volcano. The pipe duke RT length $h_{2}$ has been filled up with ocean water, while the angle $\omega$ is such that $0<\omega \leq 90^{\circ}$. The length of the pipe duke is $h_{2} \sin \omega$ ii) The formation of the sea-whirpool

Suppose that a solid body mass $\mathrm{m}$, whose specific gravity overcomes the specific gravity of water is at point $\mathrm{S}$ of the surface of the ocean, indicated in Figure 11. Then accordingly of the principle of conservation of energy:

$$
\mathrm{mg}\left(\mathrm{h}_{1}+\mathrm{h}_{2} \sin \omega\right)-\mathrm{E}_{\mathrm{b}}-\mathrm{E}_{\mathrm{r}}=0.5 \mathrm{mv}_{\mathrm{T}}{ }^{2}-4 \gamma \mathrm{h}_{2} \sin \omega(4.3)
$$

where $0<\omega \leq 90^{\circ}, \mathrm{h} 1, \mathrm{~h} 2$ are respectively: the depths of the ocean and of pipe duke of the volcano, $m g\left(h_{1}+h_{2} \sin \omega\right)$ is the dynamic energy due to position of the body, $E_{b}$ is the energy due to its buoyancy, $E_{r}$ is the energy due to the resistance of the water. Also $\mathrm{v}_{\mathrm{T}}$ is the velocity of the body when it contacts the point $\mathrm{T}$ at the bottom of the pipe duke and $0.5 \mathrm{mv}_{\mathrm{T}}{ }^{2}$ is its kinetic energy. Finally $-4 \gamma \mathrm{h}_{2} \sin \omega$ is the surface energy of the crack that filled up by magma. The sign "-" is imposed here since surface energy is a subtracted energy from the elastic energy of basalt, during the growth of crack [30].

From (4.3) it is possible to obtain:

$$
\left.\mathrm{v}_{\mathrm{T}}=\left[\begin{array}{l}
2 \mathrm{~g}\left(\mathrm{~h}_{1}+\mathrm{h}_{2} \sin \omega\right) \\
+\left[4 \gamma \mathrm{h}_{2} \sin \omega-\left(\mathrm{E}_{\mathrm{b}}+\mathrm{E}_{\mathrm{r}}\right)\right]
\end{array}\right] / \mathrm{m}\right]^{1 / 2} .
$$

If there was not a submarine volcano and the depth h2 was due to an abyssal plain indicated in Figure 12. (4.3) would be written as:

$$
\mathrm{mg}\left(\mathrm{h}_{1}+\mathrm{h}_{2} \sin \omega\right)-\mathrm{E}_{\mathrm{b}}-\mathrm{E}_{\mathrm{r}}=0.5 m \tilde{v}_{\mathrm{T}}{ }^{2} .
$$

From the above it results:

$$
\tilde{\mathrm{v}}_{\mathrm{T}}=\left[2 \mathrm{~g}\left(\mathrm{~h}_{1}+\mathrm{h}_{2} \sin \omega\right)-\left(\mathrm{E}_{\mathrm{b}}+\mathrm{E}_{\mathrm{r}}\right) / \mathrm{m}\right]^{1 / 2}
$$

Assume that we deal with a metal body and neglect its buoyancy and the resistance of the water. Then (4.4) and (4.6) become respectively:

$$
\begin{aligned}
& \mathrm{v}_{\mathrm{T}}=\left[2 \mathrm{gh}_{1}+2(\mathrm{~g}+2 \gamma / \mathrm{m}) \mathrm{h}_{2} \sin \omega\right]^{1 / 2} \\
& \text { and } \tilde{\mathrm{v}}_{\mathrm{T}}=\left[2 \mathrm{~g}\left(\mathrm{~h}_{1}+\mathrm{h}_{2} \sin \omega\right)\right]^{1 / 2} .
\end{aligned}
$$

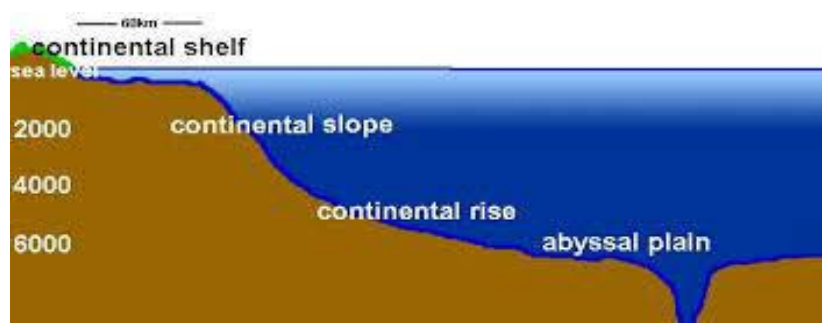

Figure 12. Abyssal plain is the vast area of the deep oceanic floor

Compare the expressions in (4.7). We observe that:

i) At case at which the depth $h_{2}$ was due to abyssial plain, the velocity given by $(4.7)_{2}$ is smaller compared with the velocity given by $(4.7)_{1}$ for our case.

ii) In (4.7) $)_{1}$ the acceleration of gravity that corresponds to the depth $h_{1}$ has the normal value g. However the acceleration of gravity that corresponds to the depth $\mathrm{h}_{2} \sin \omega$ declines from normal value because is overestimated $+2 \gamma / \mathrm{m}$. This phenomenon in the sea nature is the wellknown "sea-whirpool". Therefore after the erruption of submarine volcano, a sea-whirppol will be produced and its centre will be at point $\mathrm{S}$. 


\section{Discussion-Conclusion}

Our model agrees with results that recorded the above phenomenon in certain places in the Earth $[41,42,43,44]$ and par ticularly in Socorro Island of Mexico [41,44], in Azores [43,44] and in Monowai [43,44].

Thus we concluded that temperature significantly contributes to the growth of the cracks in a submarine volcano that is under a hot spot by increasing the lenght of crack and resulting to the fracture of the body.

\section{References}

[1] Lekkas S. (1985). "Notes of Dynamic Geology”. University of Athens, Greek.

[2] Taylor S. and McLemon S. (1985). "The continental crust: its composition and evolution”. Oxford Blackwell Scientific.

[3] Kearey P. and Vine J. (1990). "Global Tectonics. Oxford: Blac kwell Scientific Publications.

[4] Moores M. and Twiss J. (1995). "Tectonics New York: W. Freeman and Company Moores and Twiss, 1995.

[5] Olsen K. (1995). "Continental Riffts: Evolution, Structure, Tectonics”. Amsterdam, Elsevier. Olsen, 1995.

[6] Pluijim vander A. and Marshak S. (1997). "Earth Structure. An Introduction to Structural Geology.

[7] Press F. and Siever R. (1998). "Understanting Earth”. New York. W. H., Freeman and Company.

[8] Davies F. G. (1999). "Dynamics Earth". Plates, Plumes and Mantle Convection. Cambridge: Cambridge University Press Davies, 1999.

[9] Skinner J. and Porter C. (2000). “The Dynamic Earth. New York. John Wiley and Sons, Inc.

[10] Papazaxos B. and Papazaxos K. (2008). Introduction to Geophysis”. Editions Ziti, Thessaloniki, Greece (in Greek).

[11] Bowes D. R. (1989). "The encyclopedia of Igneous and Metamorphic Petrology”, Van Nostrand Reinhold.

[12] Clare P., Marshall, Rhodes W. and Fairbridge (1999). "Encyclopedia of Geochemistry, Kluer Academic Publishers.

[13] Marshak S. (2005). "Earth: Portrait of a Plannet”. pp. 41-87.

[14] Lekkas S., Lozios S and Skourtsos E. (2006). "An intro-duction to Geodynamics”, University of Athens (in Greek)

[15] Rogers N., Blake S., Burton K. (2008). "An introduction to our dynamic planet”. Cambridge University Press p. 19.

[16] McClelland L., Simkin T., Summers M., et., al., (eds.) (1989). “Gloval volcanism in 1975 -1985”. Prentice - Hall and American Geophysical Union Mc-Cleelland et., al., 1989.

[17] Simkin T., and Siebert L. (1994). "Volcanoes of the world, 2nd edition. Geoscience Press in association with the Smithsonian Institution. Global Volcanism Program, Tuscon AZ.

[18] Simkin T., Unger JD., Tilling RI., et., al., (1994). "This dynamic planet $1 \times 1.5 \mathrm{~m}$ wall map.” 2nd edition SI, USGS and NRL. 1941-1944.

[19] Siebert L., and Simkin T., (2002). "Volcanoes of the world: an illustrated catalog of holocene volcanoes and their eruptions". Smithsonian Institution. Gloval volcanism program digital information series, GVP-3. Also in: www.volcano.si.edu/world

[20] Venzke E., Wunderman R, Mc Clelland et., al., (eds.): (2002-): Gloval volcanism, 1968 to the present Smithsonian In-stitution. Global Volcanism Program, Digital Information Series GVP-4. Also in: www.volcano.si.edu/reports.

[21] Morgan W. (1968). "Rises, trenches, great faults and cry-stal blocks”. J. Geophys., Res., 73. 1969-1982.
[22] Morgan W. (1971). "Convection plumes in the lower mant-le". Nature, 230, pp., 42-43.

[23] Morgan W. (1972). "Plate motions and deep mantle con-vection". Geol. Soc.,. Am., Man., 132, pp., 7-22.

[24] Morgan W. (1983): "Hot spot tracks and early rifting of the Atlantic”. Tectonophysics, 94, 123-129.

[25] Ritter J., Jordan M., Christensen U., et., al., (2001). "A mantle plume below the Eifel volcanic fields". German, Earth Plan, Sci., Lett., 186, pp.7-14.

[26] Montelli R., Nolet G., Dahlen F., et., al., (2004) : "Finite frequency tomography reveals a variety of plumes in the mantle" Science, 303, pp., 338-343.

[27] Papazaxos K. (2006). in: www.geo.auth.gr/765/1.../15-intraplate.ht.

[28] Sih G. (2009). "Crack tip mechanics based on progressive damage of arrow. Hierarchy of singularities and multiscale segments". Theoretical and Applied, Mechanics, 51, pp. 11-32.

[29] Grifith A. (1921). "The phenomena of rupture and flow in solids" Philosophical Transactions of the Royal Society of London A 221, pp., 163-198.

[30] Griffith A. (1924). "The theory of rupture”. In: Proc., Ist., Int., Congr., Appl., Mech. Biereno, C.B. Burgers, J.M(eds). Delft: Tech. Boekhandel en Drukkerij. J. Waltman Jr., pp. 54-63.

[31] Tsoutrelis C. (1985). "Elementary rock mechanics. Part I: Basic theory and experimental method", Athens, 1985.

[32] Deere D. and Miller R. (1966): "Engineering classification and index properties for intact rock" Tech. Report No AFWL - TR-65116, Air Force Weapons Lab., Kirtland Air Base, New Mexico.

[33] Sakellariou M. (1989). "The effect of the pre - existing cracks in the distribution of the compressive stress. Appli-cation to rock mechanics area". PhD Thesis, National Tech-nical University of Athens.

[34] Bombolakis E.G. (1964). "Photoelastic investigation of brittle crack growth within a field of uniaxial compression”. Tectonophysics 1, pp. 343-351.

[35] Bombolakis E.G (1973). "Study of the brittle fracture pro-cess under uniaxial compression”. Tectonophysics 18, pp. 231-248.

[36] Hoek E. (1965). "Rock fracture under static conditions". Natl. Mech., Eng. Res. , Inst., C.S.I.R. Rept. MEG 383.

[37] Hoek E. (1968). "Brittle failure of rock in: Rock Mechanics in Engineering Practice, Stagg, K.G., Zienkiewicz O.C. (eds). London: Wiley, pp. 19-124.

[38] Bieniawski Z. T. (1967): "Mechanism of brittle fracture of rock. Part I: Theory of fracture process. Part II: Experimental studies. Part III: Fracture in tension and under long term loa-ding” Int. J. Rock Mech., Sci., 4, pp. 395-430.

[39] Bieniawski Z. T. (1981). "Rock materials under mixed mode fracture in mixed mode crack propagation”. Proc. of First USA GREECE Symposium eds. Sih and Theocharis P. Athens, 1980. Sijthoff \& Noordhooff. The Netherlands.

[40] Cotterel B. (1972): "Brittle fracture in compression”. Int., J., Fract., Mech., vol. 8, pp. 195-208.

[41] Siebe C., Komorowski JC., Navaro C., et., al., (1995). "The 1993 submarine eruption near Socorro Island Mexico". J. of Volcanology and Geothermal Research, 68, pp., 239-271.

[42] Gaspar JL, Queiroz G., Pachero JM., et., al., (2003). "Ba-saltic lava ballons produced during 1998 - 2001.Serreta Sub-marine Ridge eruption (Azores) in : White DJL et., al., edited: "Explosive Subaqueous Volcanism American Geophysical Union Monograph, 140 , p. 205-212.

[43] Watts A.B., Peirce C., Grevemeyer I., et., al., (2012). "Rapid rates of growth and collaps of Monowai submarine volcano in the Kermadec Arc”. Nature Geoscience, 5, pp., 510-515.

[44] Schmincke H-U and Sumitu M. (2013). "Fire in the sea. Growth and destruction of submarine volcanoes". Geology, 41, no 3, p. 381-382. 